\title{
A Dynamic Model of Firms' Strategic Location Choice
}

\author{
Luca Colombo ${ }^{1}$ and Herbert Dawid ${ }^{2(凶)}$ \\ 1 Department of Economics and Finance, Università Cattolica del Sacro Cuore, \\ Largo Gemelli 1, 20123 Milano, Italy \\ lucava.colombo@unicatt.it \\ 2 Department of Business Administration and Economics \\ and Center for Mathematical Economics, Bielefeld University, \\ P.O. Box 100131, 33501 Bielefeld, Germany \\ hdawid@wiwi.uni-bielefeld.de
}

\begin{abstract}
This paper analyzes the optimal location choice of a firm in a dynamic Cournot framework, in which firms' absorptive capacities may depend on their knowledge stock. The firm decides whether to locate irreversibly in a cluster or in isolation. In the cluster the firm benefits from inward spillovers from its competitors, but also generates outward spillovers. If the firm chooses to locate in isolation no knowledge flows occur. All firms' production costs are determined by their knowledge stocks, which evolve over time due to own $R \& D$ investments and potentially inward spillovers. It is shown that, if absorptive capacity is constant, the incentive to locate in the cluster decreases with respect to the firm's knowledge stock. Conversely, if absorptive capacity depends positively on knowledge stock, the firm's incentive to join the cluster is larger the more knowledge it has. It is also shown that qualitative properties of the equilibrium paths of R\&D investments and knowledge stocks differ substantially depending on whether absorptive capacities are constant or knowledge dependent.
\end{abstract}

\section{Introduction}

Firms' location choices are affected by several factors. In particular, the pertinent literature - often focusing on the choices of multinational firms - has highlighted the role of the proximity to sales and factor markets, that of the local institutions and regulations, and that of local labor markets, especially in relation to availability of the appropriate skill mix (see e.g. Almazan et al. 2007; Lee and Mansfield 1996; Henisz 2000; De Beule and Duanmu 2012). Somewhat surprisingly, the effects of inward and (especially) outward knowledge spillovers on the location choices of firms have not received much attention, although such spillovers are known to have a large impact on firms' decisions. Given that knowledge is in many cases tacit and localized, a firm's ability to benefit from

Financial support under COST Action IS1104 "The EU in the new economic complex geography: models, tools and policy evaluation" is gratefully acknowledged.

(C) The Author(s) 2018

P. Commendatore et al. (eds.), The Economy as a Complex Spatial System,

Springer Proceedings in Complexity, DOI 10.1007/978-3-319-65627-4_9 
knowledge flows and the associated spillovers is likely to depend to a large extent on geographical proximity. This establishes an immediate link between the relevance of knowledge spillovers and firms' strategic location choices, which is confirmed by the findings of a relatively recent (and mainly) empirical literature on the borders between Management and Industrial Organization. Alcacer and Chung (2007) find that technologically advanced firms tend to avoid locations with strong industrial activity in an attempt to distance themselves from competitors, favoring instead areas characterized by high levels of academic activity. Knowledge spillovers - more precisely, the consideration of the gains from inward spillovers (the opportunity for knowledge sourcing from other firms in the same location) vs. the costs of outward spillovers - are argued to lie at the hearth of the observed location choices. Along the same lines, Leiponen and Helfat (2011) show that firms mainly involved with imitative innovation tend to choose multiple locations for their R\&D activities, while firms mainly dealing with 'new to the market' innovations do not. The heterogeneity between the location choices of the two types of firms can again be easily related to the differential impact of knowledge spillovers. The relevance of knowledge spillovers in clusters has been the object of a large literature (see e.g. Griliches 1992; Jaffe et al. 1993) mainly emphasizing the positive externalities - in terms of knowledge generation dynamics - stemming from firms' agglomerations (Head et al. 1995). The importance of outward spillovers - obviously a negative externality of local agglomerations has been instead substantially underweighted in the literature, at least until Alcacer and Chung (2007). ${ }^{1}$

As already noted, despite the abundance of empirical and anecdotal evidence about the importance of knowledge spillovers for firms' location choices, relatively little theoretical work has been done but for a few notable exceptions. For instance, Gersbach and Schmutzler (1999) focus on the effects of internal and external knowledge spillovers on the location of production and innovative activities in a Bertrand duopoly. Knowledge spillovers play a role also in Piga and Poyago-Theotoky (2005) that focus on a Hotelling-type oligopoly where firms choose their locations, as well as their R\&D efforts and prices. In their framework, however, firms' choices depend crucially on transportation costs that play no role at all in our setup. ${ }^{2}$ Quite a few papers investigate the location choices of multinational firms. Among them, Gersbach and Schmutzler (2011) focus on the location of the production and R\&D activities of multinational firms in the presence of knowledge sourcing. Belderbos et al. (2008) build on Gersbach and Schmutzler's (1999) setup to investigate the strategic location of R\&D by two

${ }^{1}$ More recently, Mariotti et al. (2010) have stressed the negative role of technological leakages in the location decisions of multi-national firms, qualitatively confirming Alcacer and Chung's (2007) key insights. Furthermore, Belderbos et al. (2008) have shown that technological leaders are more attracted than followers by countries endowed with better intellectual property right protection mechanisms, indirectly confirming that firms are afraid of possible outward spillovers.

2 Note that in Piga and Poyago-Theotoky (2005) firms choose from a continuum of locations, while here - as in most of the literature - we focus on a binary choice only: either firms locate in a cluster or in isolation. 
multinational firms (a technological leader and a laggard) competing in their home markets and abroad, showing that the fraction of R\&D located abroad depends on the extent of inward and outward spillovers, on product market competition, as well as on the gap between the technological leader and the laggard. ${ }^{3}$

A fundamental difference between all these papers and our contribution is that they focus on essentially static frameworks, so that they cannot investigate how the dynamics of knowledge and profits affect firms' location decisions, as well as the differences between their short run and long run implications. In Colombo and Dawid (2014) we make a first attempt at modeling firms' strategic location choices - considering the binary choice of clustering vs. isolation in a dynamic game-theoretic framework by putting the role of inward and outward spillovers on the front stage. That paper develops a differential game setup studying the conditions under which it is optimal for a firm to locate inside or outside an R\&D cluster, focusing also on how firms' incentives depend on the intensity of knowledge spillovers in the cluster, on the degree of competition in the industry, and on firms' planning horizons. Furthermore, it characterizes the effects of firms' location choices on social welfare in the long run, providing a normative base on which to ground the evaluation of alternative policies. ${ }^{4}$ To be more specific, we consider a differential game with $n$ firms producing at each time $t$ a homogeneous good and competing in a common market. Firms' production costs are decreasing in their knowledge stock, which can be improved through R\&D. The industry is characterized by the presence of a cluster of firms and each firm can either decide to locate in the cluster, or in isolation. By locating in the cluster, a firm can benefit from knowledge spillovers that depend on the overall knowledge stock of all the firms belonging to the cluster, while by locating in isolation a firm cannot benefit from inward spillovers neither suffer from outward spillovers. We solve the game by first characterizing the feedback strategies of the firms in the cluster and in isolation with respect to their $R \& D$ investments in a Markov perfect equilibrium for an arbitrary location pattern of firms. We then investigate the incentives to locate in the cluster or in isolation by comparing the numerically determined value functions under the Markov perfect equilibrium of the differential game for the two location scenarios.

We focus in particular on the location choice of a firm - a technological leader - that is either more efficient in performing R\&D than its competitors, because of a structural advantage, or has only an initial advantage with respect to the size of its knowledge stock. Under the assumption that the technological leader enjoys a structural advantage, we show that it adopts a 'threshold'

${ }^{3}$ The location of R\&D by multinational firms in the presence of spillovers is also the focus e.g. of Petit and Sanna-Randaccio (2000); Ekholm and Hakkala (2007); Alcacer and Zhao (2012), although their research questions differ substantially from the one we focus on here.

4 Also Alcacer et al. (2013) highlight the role of dynamic strategic interactions on (multinational) firms' location choices, although they concentrate on the effects of firms' decisions on an industry competitive environment. 
strategy, choosing to locate outside the industry cluster whenever its advantage over the competitors is sufficiently large. Two major forces are at play in our dynamic setup. In the short run, the leader benefits from locating in the cluster as its investment there is lower than in isolation. This follows immediately from the observation that, when in the cluster, the leader's R\&D efforts end up reducing the future costs faced by competitors. In the long run, however, the leader is worse off in the cluster than in isolation (i.e. it has a lower market share), due to the faster catching-up of the followers that benefit from the outward spillovers generated by the presence of the technological leader in the cluster. The relative strength of the short run investment effect vs. that of the long run market share effect determines whether - for given intensity of the knowledge spillovers - the technological leader chooses to locate in the cluster or in isolation. The threshold at which the location choice of the leader switches from cluster to isolation is shown to be increasing in the discount rate - indicating that the more myopic the leader is the larger are its incentives to join the cluster, as well as in the dispersion of the industry and in the intensity of spillovers - suggesting that the leader's incentives to join the cluster are larger the higher the number of competitors is and the more pervasive spillovers are.

The implications of the model are entirely different when focusing on the case in which the technological leader enjoys an initial knowledge advantage only, as it is often the case for market pioneers in new sub-markets within an industry. Although the leader's location choice between the cluster and isolation is still determined by a threshold strategy, both the long run profits and the knowledge stock of the leader are larger when locating in the cluster rather than in isolation (exactly the opposite of what happens under a structural advantage). This follows immediately from the observations that, under a temporary knowledge advantage, in the long run the balance between outward and inward spillovers is the same for both the leader and its competitors (whereas under a structural advantage the wedge between the two is systematically larger for the leader than for the competitors), and that by locating in the cluster the leader can benefit from the spillovers generated by the competitors, which would instead be absent were it to locate in isolation. Similar arguments explain the opposite results we find in this case with respect to the structural advantage one in terms of comparative statics, with a negative relationship between the leader's location threshold and firms' discount rate.

Interestingly, both under a structural and a temporary R\&D advantage of the leader, our numerical simulations show the existence of scenarios in which, although the technological leader chooses to locate in isolation, both total industry profits and consumers' surplus would be larger if it were to locate in the cluster. Hence, the leader's optimal choice contrasts with the socially optimal one. This inefficiency result is easily understood by noting that locating in the cluster the leader would strengthen competition, hence reducing market price and correspondingly increasing consumers' surplus; an effect that the leader has no incentives to take into account. 
A clear limitation of the analysis of Colombo and Dawid (2014) is that all firms are assumed to be equally able to assimilate and exploit the knowledge generated by other firms. Cohen and Levinthal (1989), and the literature originating from their seminal contribution, emphasize instead that a firm's ability to effectively use external information depends also on its own R\&D. Indeed, besides generating innovations, $\mathrm{R} \& \mathrm{D}$ is argued to enhance a firm's ability to "identify, assimilate, and exploit knowledge from the environment .... encompassing a firm's ability to imitate new process or innovations [but also] outside knowledge of a more intermediate sort" (Cohen and Levinthal 1989, p. 369); what the authors label as absorptive capacity. As R\&D contributes to a firm's absorptive capacity, the incentives to spend in R\&D are affected by the firm's available knowledge base and by the ease of learning external technological and scientific knowledge. In our terminology, this translates into the observation that the ability of a firm to benefit from inward spillovers depends on its absorptive capacity, while the magnitudes of the outward spillovers it generates depend on that of competitors.

The main purpose of this chapter is to explicitly account for the effects of absorptive capacities on knowledge spillovers and to investigate their impact on firms' location choices. We do so by augmenting the framework in Colombo and Dawid (2014), a detailed summary of which has been provided above, by allowing for differences in absorptive capacities across firms. In particular, we extend the setting of Colombo and Dawid (2014) by considering in addition to the case of constant absorptive capacity also that in which absorptive capacity is proportional to the firm's knowledge stock. In the latter case, the resulting differential game does not have a linear-quadratic structure and we rely on numerical methods to approximately solve the Hamilton-Jacobi-Bellman equations characterizing the value functions corresponding to Markov Perfect Equilibria of the game for different location choices. Interestingly, the insight in Colombo and Dawid (2014) that a technological leader has higher incentives than a laggard to locate in isolation is reversed if the absorptive capacity is proportional to the knowledge stock. In particular, in the latter case it is optimal for the firm to locate in the cluster only if its knowledge stock is substantially larger than that of its competitors. Furthermore, we show that a knowledge dependent absorptive capacity also gives rise to different strategic effects, as well as different dynamic patterns of R\&D investment and knowledge accumulation, compared to the case of constant absorptive capacity. Specifically, the strategic implications of locating in the cluster are reversed. Under constant absorptive capacity, the other firms in the cluster increase their R\&D investments if an additional firm enters, whereas under knowledge dependent absorptive capacity the opposite occurs. Also, under knowledge dependent absorptive capacity, a technological leader is able to keep its advantage for an extended time window even when entering the cluster, which makes this location choice more attractive. Conversely, for a firm with a small initial knowledge stock locating in the cluster becomes less attractive if the absorptive capacity depends on knowledge, because at least initially this firm can hardly profit from inward spillovers. 
The chapter is organized as follows. Section 2 introduces our model. Section 3 characterizes Markov-perfect equilibria and describes the usage of collocation methods in our numerical analysis. Section 4 discusses the incentives of firms to locate in an industrial cluster rather than in isolation, as a function of knowledge spillovers and of firms absorptive capacity. Section 5 concludes.

\section{The Model}

We investigate the location choice of a firm competing in a dynamic Cournot oligopoly market consisting of three firms, which at each point in time $t \geq 0$ simultaneously choose the quantities of a homogeneous good. Following Colombo and Dawid (2014), we focus on an economy with a representative consumer whose preferences are described by a quadratic Dixit-Stiglitz utility function yielding an inverse demand function of the form

$$
p(t)=a-b \sum_{j=1}^{3} q_{j}(t), a, b>0,
$$

where $q_{j}(t) \geq 0$ denotes the quantity of firm $j$ and $p(t)$ is the price of the good at time $t$.

We assume that all firms have constant marginal costs. More specifically, the level of marginal costs of firm $i$ at time $t, c_{i}(t)$, depends in a linear way on its stock of (cost-reducing) knowledge $k_{i}(t)$ at time $t$, i.e.

$$
c_{i}(t)=\bar{c}-\gamma k_{i}(t), \bar{c}, \gamma>0 .
$$

This formulation implies that in the absence of any cost-reducing knowledge all firms have identical marginal costs. To avoid negative marginal costs, we add the state constraint

$$
k_{i}(t) \leq \frac{\bar{c}}{\gamma} \quad i=1, . ., 3
$$

We concentrate on the location decision of firm $i=1$ that, at time $t=0$, chooses whether to locate in an industrial cluster or in isolation. By locating in the cluster the firm is exposed to inward and outward knowledge spillovers, affecting the dynamics both of its own knowledge stock and of that of its competitors. We assume that the two competitors of firm 1, firms $i=2,3$ are located in the industrial cluster. ${ }^{5}$ Each firm in the cluster receives spillovers from all other firms in the cluster and transfers (a fraction of) its own knowledge to the other firms in the cluster. The intensity according to which firm $i$ can transform incoming spillovers into own knowledge depends on the firm's absorptive capacity, $\kappa_{i}\left(k_{i}\right)$. In what follows we consider two specifications. In the first, we assume that absorptive capacity is independent from the firms' knowledge stock, i.e. $\kappa_{i}\left(k_{i}\right)=\kappa^{\text {const }} \forall k_{i} \geq 0$ and we normalize $\kappa^{\text {const }}$ to 1 . In the second,

\footnotetext{
${ }^{5}$ We focus on three firms as it is the lowest number of firms such that spillovers arise in the cluster even if one of the firms decides to locate outside the cluster.
} 
we consider a scenario in which absorptive capacity is proportional to the firm's knowledge stock, i.e. $\kappa_{i}\left(k_{i}\right)=\kappa^{l i n}\left(k_{i}\right):=\xi k_{i}$.

Rather than locating in the cluster, firm 1 can decide to locate in isolation, where it is not affected by inward or outward spillovers. To keep our analysis as simple as possible, we assume that there are no direct costs associated with either of the two location choices and that no relocation is possible at any point in time $t>0 .{ }^{6}$ However, in order to capture congestion in the cluster (e.g. in terms of higher rental costs for production facilities), we assume that the firms located in the cluster suffer a fixed cost $F>0$ per period, whereas the corresponding cost is normalized to zero if a firm locates in isolation.

Formally, firm 1 chooses its location $l_{1} \in\{C, I\}$ at $t=0$. Following again Colombo and Dawid (2014), we denote with $N_{C} \subseteq\{1, . ., 3\}$ the set of firms in the cluster, where $\left|N_{C}\right|=n_{C} \leq 3$. The overall number of firms located in the cluster is then $n_{C}$. Having assumed that the competitors of firm 1 are in the cluster implies that $l_{2}=l_{3}=C$. The knowledge stock of firm $i$ depends positively on its R\&D effort, $x_{i}$, and negatively on knowledge depreciation, which is assumed to occur at the same rate $\delta>0$ for all firms. Furthermore, firms in the cluster benefit from inward spillovers. Formally, we have

$$
\dot{k}_{i}(t)=\left\{\begin{array}{ll}
x_{i}(t)+\beta \kappa_{i}\left(k_{i}\right) \sum_{j \in N_{C} \backslash\{i\}} k_{j}(t)-\delta k_{i}(t) & l_{i}=C \\
x_{i}(t)-\delta k_{i}(t) & l_{i}=I
\end{array} .\right.
$$

The parameter $\beta>0$ captures the general intensity of spillover flows in the cluster - that may depend on the characteristics of the key technology in the considered industry, or on the institutional properties of the cluster - and $\kappa_{i}$ denotes the specific absorptive capacity of firm $i$. This formulation is fully consistent with the observation, well established empirically, that a firm typically acquire knowledge by interacting with the other firms in its proximity (see e.g. Jaffe et al. (1993); Saxenian (1994)).

The R\&D activities of firm $i, i=1, . ., 3$, are associated to the quadratic cost function

$$
g_{i}\left(x_{i}\right)=\frac{\eta_{i}}{2} x_{i}^{2}
$$

whereas in principle we allow for heterogeneous $R \& D$ cost functions, in the numerical analysis below we will only consider scenarios in which all firms are symmetric in this respect, i.e. $\eta_{1}=\eta_{2}=\eta_{3}$.

All firms are assumed to maximize their discounted profits. Hence, the decision problem of the generic firm $i$ is given by

$$
J_{i}=\int_{0}^{\infty} e^{-r t}\left[\left(p(t)-c_{i}(t)\right) q_{i}(t)-g_{i}\left(x_{i}(t)\right)\right] d t,
$$

subject to (1), (2), (4) the constraints $(3),\left(q_{i}(t), x_{i}(t)\right) \geq 0$, and $k_{i}(0)=k_{i}^{i n i}$, for a given distribution of initial knowledge $\left(k_{1}^{i n i}, k_{2}^{i n i}, k_{3}^{i n i}\right)$.

$\overline{6}$ The decision to relocate often implies substantial transaction costs and therefore it is typically a long run decision. 
Recalling that in our setup firm 1 is the only one having the possibility to choose where to locate, its choice variables are the initial location choice, $l_{1}$, and - at each point in time $t \geq 0$ - the R\&D effort, $x_{1}(t)$, and the output quantity, $q_{1}(t)$. Instead, firms 2 and 3 - being both located in the cluster - only choose $x_{i}(t)$ and $q_{i}(t), i=2,3$, at each point in time $t \geq 0$.

\section{Markov Perfect Equilibria}

We investigate the optimal location choice of firm 1 under the assumption that for any given profile of location choices the two dynamic decision variables of each firm $\left(x_{i}(t), q_{i}(t)\right), i=1, . ., 3$ are chosen according to a Markov Perfect Equilibrium (MPE) of the underlying differential game. Taking into account that the quantity choices of firms have no intertemporal effects, it follows that at each point in time in equilibrium firms choose Cournot quantities given the current profile of marginal costs. More precisely, the equilibrium quantities are given by

$$
q_{i}^{*}\left(k_{1}, . ., k_{3}\right)=\frac{a-\bar{c}+\gamma\left(3 k_{i}-\sum_{j \neq i} k_{j}\right)}{4 b}
$$

and the resulting instantaneous profits at each point in time read

$$
\pi_{i}^{*}\left(x_{i}, k_{1}, . ., k_{3}\right)=\frac{\left(a-\bar{c}+\gamma\left(3 k_{i}-\sum_{j \neq i} k_{j}\right)\right)^{2}}{16 b}-g_{i}\left(x_{i}\right) .
$$

Hence, we can rewrite (5) as

$$
J_{i}=\int_{0}^{\infty} e^{-r t} \pi_{i}^{*}\left(x_{i}, k_{1}, . ., k_{3}\right) d t
$$

Concerning R\&D investments, a Markovian feedback strategy of firm $i$ takes the form

$$
\phi_{i}\left(k_{1}, . ., k_{3}\right), i=1, . ., 3 \text { with } \phi_{i}:\left[0, \frac{\bar{c}}{\gamma}\right]^{3} \rightarrow[0, \infty)
$$

A profile $\left(\phi_{1}, \ldots, \phi_{3}\right)$ of feedback strategies constitutes a Markov Perfect Equilibrium if, for each firm $i$, the strategy $\phi_{i}$ maximizes (8) subject to (4) as well as $x_{i} \geq 0$ and the initial conditions, given that the other firms use $\phi_{j}, j \neq i$. Although in general the existence and uniqueness of a MPE cannot be guaranteed, our numerical procedure always yields a unique MPE profile for each parameter setting and location choice. We denote the MPE profile resulting from firm 1 locating in the cluster as $\left(x_{1}^{C}, . ., x_{3}^{C}\right)$, whereas we refer to the MPE with firm 1 locating in isolation as $\left(x_{1}^{I}, . ., x_{3}^{I}\right)$. The following proposition characterizes for both location scenarios firms' equilibrium investment strategies in terms of the corresponding value functions $V_{i}^{C}$ and $V_{i}^{I}$, respectively. 
Proposition 1. For a given location choice of firm $1, l_{1} \in\{C, I\}$, any profile of MPE investment strategies has to satisfy

$$
x_{i}^{l}=\frac{1}{\eta_{i}} \frac{\partial V_{i}^{l}}{\partial k_{i}}, i=1, . ., 3,
$$

where the value functions $V_{i}^{l}$ solve the following Hamilton Jacobi Bellman (HJB) equations:

$$
\begin{aligned}
r V_{i}^{C}= & \max _{x_{i} \geq 0}\left[\pi_{i}^{*}\left(x_{i}, k_{1}, . ., k_{3}\right)-F+\left(x_{i}+\beta \kappa_{i}\left(k_{i}\right) \sum_{j \neq i} k_{j}-\delta k_{i}\right) \frac{\partial V_{i}^{C}}{\partial k_{i}}\right. \\
& \left.+\sum_{j \neq i}\left(x_{j}^{C}+\beta \kappa_{j}\left(k_{j}\right) \sum_{m \neq j} k_{m}-\delta k_{j}\right) \frac{\partial V_{i}^{C}}{\partial k_{j}}\right] \\
r V_{1}^{I}= & \max _{x_{1} \geq 0}\left[\pi_{1}^{*}\left(x_{1}, k_{1}, . ., k_{3}\right)+\left(x_{1}-\delta k_{1}\right) \frac{\partial V_{1}^{I}}{\partial k_{1}}\right. \\
& \left.+\left(x_{2}^{I}+\beta \kappa_{2}\left(k_{2}\right) k_{3}-\delta k_{2}\right) \frac{\partial V_{1}^{I}}{\partial k_{2}}+\left(x_{3}^{I}+\beta \kappa_{3}\left(k_{3}\right) k_{2}-\delta k_{3}\right) \frac{\partial V_{1}^{I}}{\partial k_{3}}\right] \\
r V_{2}^{I}= & \max _{x_{2} \geq 0}\left[\pi_{2}^{*}\left(x_{2}, k_{1}, . ., k_{3}\right)-F+\left(x_{1}^{I}-\delta k_{1}\right) \frac{\partial V_{2}^{I}}{\partial k_{1}}\right. \\
& \left.+\left(x_{2}+\beta \kappa_{2}\left(k_{2}\right) k_{3}-\delta k_{2}\right) \frac{\partial V_{2}^{I}}{\partial k_{2}}+\left(x_{3}^{I}+\beta \kappa_{3}\left(k_{3}\right) k_{2}-\delta k_{3}\right) \frac{\partial V_{2}^{I}}{\partial k_{3}}\right] \\
r V_{3}^{I}= & \max _{x_{3} \geq 0}\left[\pi_{3}^{*}\left(x_{3}, k_{1}, . ., k_{3}\right)-F+\left(x_{1}^{I}-\delta k_{1}\right) \frac{\partial V_{3}^{I}}{\partial k_{1}}\right. \\
& \left.+\left(x_{2}^{I}+\beta \kappa_{2}\left(k_{2}\right) k_{3}-\delta k_{2}\right) \frac{\partial V_{3}^{I}}{\partial k_{2}}+\left(x_{3}+\beta \kappa_{3}\left(k_{3}\right) k_{2}-\delta k_{3}\right) \frac{\partial V_{3}^{I}}{\partial k_{3}}\right]
\end{aligned}
$$

Proof. The structure of the HJB equations follows from standard characterizations of Markov Perfect Equilibria (see e.g. Dockner et al. (2000)) and the expression (9) for the optimal investment is immediately obtained from the first order conditions of the right hand side of (10).

If $\kappa_{i}=\kappa^{\text {const }}$, then the considered game corresponds to that analyzed by Colombo and Dawid (2014) and it has a linear-quadratic structure. In this case, the MPE under the different location choices of firm 1 give rise to value functions that are quadratic in the state variables and the set of HJB equations (10) can be easily solved taking this into account.

For $\kappa_{i}=\kappa^{l i n}$ the right hand side of the HJB equations (10) includes terms where the state derivative of the value function is multiplied by an expression that is non-linear in the state variables. This implies that no polynomial value functions exist for the problem and we cannot provide an analytical characterization of the value functions. Hence, we rely on numerical methods to solve the HJB equations and to characterize the equilibrium investment functions. In particular, we employ a collocation method using Chebychev polynomials (see e.g. Dawid et al. (2017)) in order to obtain an approximate solution to the HJB equations (10). We determine polynomial approximations $\hat{V}_{i}^{C}$, respectively $\hat{V}_{i}^{I}$, such that (10), after substituting (9) for the optimal investment, is satisfied on a finite set of nodes in the state-space and it exhibits small differences between the left- and the right-hand side of the equations for all other points in the state space. To this end, we generate a set of $n_{i}$ Chebychev nodes $\mathcal{N}_{k_{i}}$ in $[0, \bar{k}]$ for $i=1, . ., 3$ and some $\bar{k}<\frac{\bar{c}}{\gamma}$ (see e.g. Judd (1998) for the definition of Chebychev 
nodes and Chebychev polynomials) and we define the set of interpolation nodes in the state space $[0, \bar{k}]^{3}$ as

$$
\mathcal{N}=\left\{\left(k_{1}, k_{2}, k_{3}\right) \mid k_{i} \in \mathcal{N}_{k_{i}}\right\} .
$$

As a set of basis functions for the polynomial approximation of the value function, we use $\mathcal{B}=\left\{B_{j, k, l}, j=1, . ., n_{1}, k=1, . ., n_{2}, k=1, . ., n_{3}\right\}$ with

$$
B_{j, k, l}\left(k_{1}, k_{2}, k_{3}\right)=T_{j-1}\left(-1+\frac{2 k_{1}}{\bar{k}}\right) T_{k-1}\left(-1+\frac{2 K_{2}}{\bar{k}}\right) T_{l-1}\left(-1+\frac{2 K_{3}}{\bar{k}}\right),
$$

where $T_{j}(x)$ denotes the $j$-the Chebychev polynomial. Since Chebychev polynomials are defined on $[-1,1]$, the state variables have to be transformed accordingly.

The value function is approximated by

$$
\begin{gathered}
V_{i}^{h}\left(k_{1}, k_{2}, k_{3}\right) \approx \hat{V}\left(k_{1}, k_{2}, k_{3}\right)=\sum_{j=1}^{n_{1}} \sum_{k=1}^{n_{2}} \sum_{l=1}^{n_{3}} C_{j, k, l}^{h} B_{j, k, l}\left(k_{1}, k_{2}, k_{3}\right), \\
k_{1}, k_{2}, k_{3} \in[0, \bar{k}] ; i=1, . ., 3 ; h=C, I,
\end{gathered}
$$

where $C^{h}=\left\{C_{j, k, l}^{h}\right\}$ with $j=1, . ., n_{1}, k=1, . ., n_{2}, l=1, . ., n_{3}$ and $h=C, I$ is the set of $n_{1} n_{2} n_{3}$ coefficients to be determined for each location choice $h=C, I$. To calculate these coefficients we solve the system of non-linear equations derived from the condition that $\hat{V}_{i}^{C}$ satisfies the HJB equation (10) on the set of interpolation nodes $\mathcal{N}$. To this end, an initial guess $\tilde{C}^{h, 0}=\left(C_{j, k, l}^{h, 0}\right)_{j, k, l=1, . ., n_{1}, n_{2}, n_{3}}$ of the coefficients is chosen, and in iteration $m \geq 1$ the coefficients $\tilde{C}^{h, m-1}$ are used to calculate approximations of the value functions and their partial derivatives at each node in $\mathcal{N}$. These approximations are inserted for all terms that occur in (10), after insertion of (9), where the value function or its derivatives appear in a non-linear form. Inserting the approximation (11) with $C^{h}$ replaced by $\tilde{C}^{h, m}$ for all terms in (10), where the value function and its derivatives occur in a linear way, yields a linear system of equations for the coefficients $\tilde{C}^{h, m}$ that can be solved efficiently using standard methods, even for large values of $n_{i}, i=1, \ldots, 3$, as long as the coefficient matrix is well conditioned. The solution of this linear system gives the new set of coefficient values $\tilde{C}^{h, m}$. To complete the iteration, the new approximations of the value functions and their derivatives are inserted into all (including the non-linear) corresponding terms in (10) and (9), and the resulting absolute value of the difference between left and right hand side of this equation relative to the corresponding value function is determined for all nodes in $\mathcal{N}$. If the maximum of this relative error is below a given threshold $\epsilon$ the algorithm is stopped. It is then checked that the absolute value of the difference between the left and the right hand side of (10) is sufficiently small on the entire state space, and if this is satisfied we set $C^{h}=\tilde{C}^{h, m}$ and the current approximation of the value function is used to calculate the equilibrium feedback function according to (9). If the error outside $\mathcal{N}$ is too large, the number of considered nodes or the size of the state space are adjusted and the procedure is repeated. 
As a final step, it is checked that the considered state space $[0, \bar{k}]^{3}$ is invariant under the state dynamics induced by the equilibrium feedback functions determined by the numerical method. In the following numerical calculations, the parameters of the collocation procedure have been set to $n_{1}=n_{2}=n_{3}=6$, $\bar{k}=80$ and $\epsilon=10^{-6}$. The rationale underlying this parameter configuration is the aim to keep the number of considered nodes as small as possible while keeping the error small. With respect to the model parameters we stay as close as possible to Colombo and Dawid (2014) in order to ensure the comparability of our findings across the two settings, and use

$$
\begin{aligned}
& a=100, b=1, \gamma=0.22, \bar{c}=60, \beta=0.01, \delta=0.1, r=0.05, \xi=0.025, \\
& \eta_{i}=\eta=10, i=1, . ., 3, F=10 .
\end{aligned}
$$

\section{Economic Analysis}

In what follows, we compare the equilibrium outcomes and the induced location choice of firm 1 in the benchmark case in which absorptive capacity is independent from the firm's knowledge stock $\left(\kappa_{i}=\kappa^{\text {const }}\right)$ with a situation in which it depends positively on the firm's knowledge stock $\left(\kappa_{i}=\kappa^{l i n}\right)$.

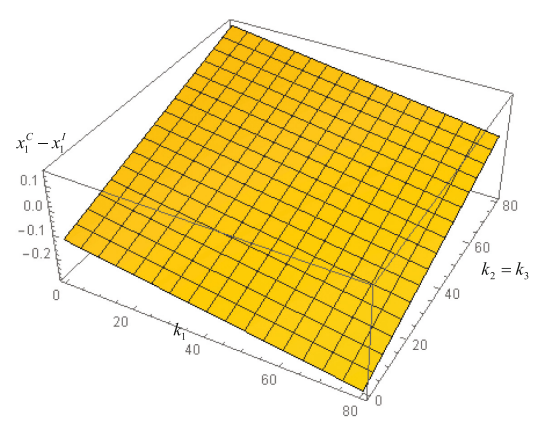

(a)

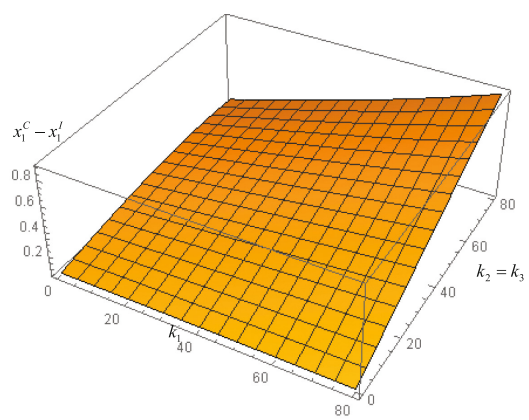

(b)

Fig. 1. Difference in equilibrium R\&D investments if firm 1 locates in the cluster and in isolation, for (a) $\kappa_{i}=\kappa^{\text {const }}$ and (b) $\kappa_{i}=\kappa^{\text {lin }}$

Although our main focus is on the optimal location decision of firm 1 , it is instructive to characterize the incentives of firm 1 to invest in R\&D depending on whether it is in the cluster or in isolation, for $\kappa_{i}=\kappa^{\text {const }}$ and $\kappa_{i}=\kappa^{\text {lin }}$, respectively. Figure 1 displays the difference between firm 1's equilibrium investment when it locates in the cluster and in isolation under the assumption that the two competitors have the same knowledge stock (i.e. $k_{2}=k_{3}$ ). Panel (a) shows that under constant absorptive capacity firm 1 invests more in the cluster than in isolation if its own knowledge stock is substantially smaller than that of its competitors. In such a situation, firm 1 expects to catch-up quickly in 
terms of its knowledge stock if it locates in the cluster, whereas the gap to its competitors will be closed at a much slower pace if it locates in isolation. Since a gap in the knowledge stock translates into higher marginal costs and a lower market share, the incentives to invest in (unit cost reducing) innovation is lower if firm 1 locates in isolation. A similar rationale explains why under constant absorptive capacity firm 1 invests less in the cluster than in isolation if it is a technological leader (i.e. if $k_{1}$ is larger than $k_{2}=k_{3}$ ). Furthermore, it should be noted that for a given level of $k_{2}=k_{3}$ the difference $x_{1}^{C}-x_{1}^{I}$ becomes smaller as the knowledge stock of firm 1 increases. To obtain an intuitive understanding for this relationship observe that a marginal increase of the knowledge stock of firm 1 induces a positive externality on the competitors' knowledge stock if firm 1 is in the cluster. Hence, the positive effects on the future market share of firm 1 are smaller compared to the scenario in which the firm is in isolation. This implies that the positive effect of an increase of $k_{1}$ on R\&D incentives is larger if firm 1 locates in isolation rather than in the cluster.

As it can be seen in panel (b), if absorptive capacity depends on the firm's knowledge stock we reach completely different conclusions. Indeed, for $\kappa_{i}=\kappa^{\text {lin }}$ firm 1 invests more if located in the cluster rather than in isolation regardless of the (relative) size of the firms' knowledge stock. Also, the difference between $x_{1}^{C}$ and $x_{1}^{I}$ is always increasing in $k_{1}$, with a slope that becomes larger the larger the competitors' knowledge stock is. Intuitively, if absorptive capacity depends on knowledge stock, then increasing $k_{1}$ has a positive impact on the size of future inward spillovers, which increases the future market share of firm 1 if it locates in the cluster. Clearly, this effect is absent if firm 1 is in isolation, which explains why for a knowledge dependent absorptive capacity R\&D incentives grow faster with $k_{1}$ if the firm locates in the cluster.

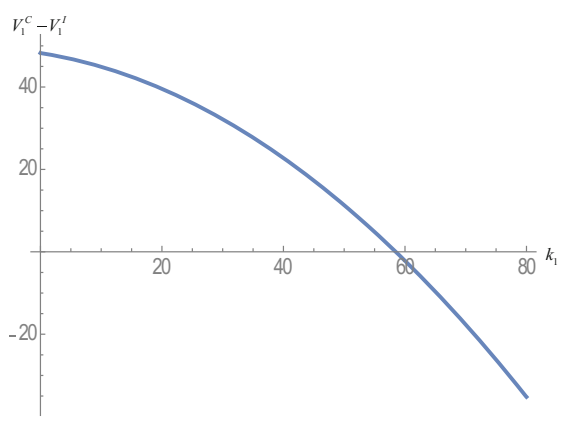

(a)

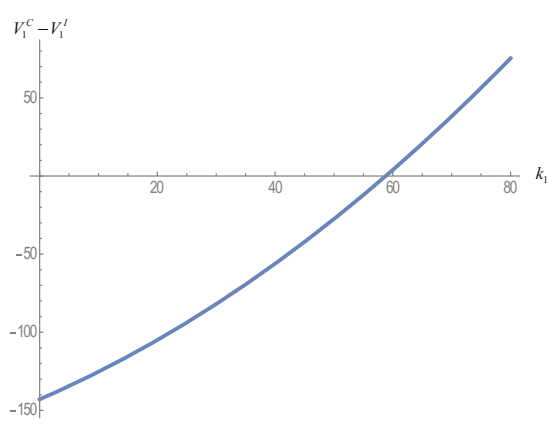

(b)

Fig. 2. Difference in value functions if firm 1 locates in the cluster and in isolation depending on the initial knowledge stock of firm 1 , for (a) $\kappa_{i}=\kappa^{\text {const }}$ and (b) $\kappa_{i}=\kappa^{\text {lin }}$

Having studied firm 1's optimal R\&D investment as a function of location, we now turn to the analysis of its optimal location choice. Figure 2 shows the difference in the value function of firm 1 between locating in the cluster and 


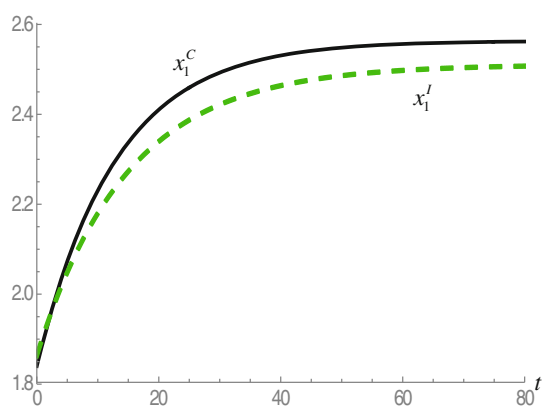

(a)

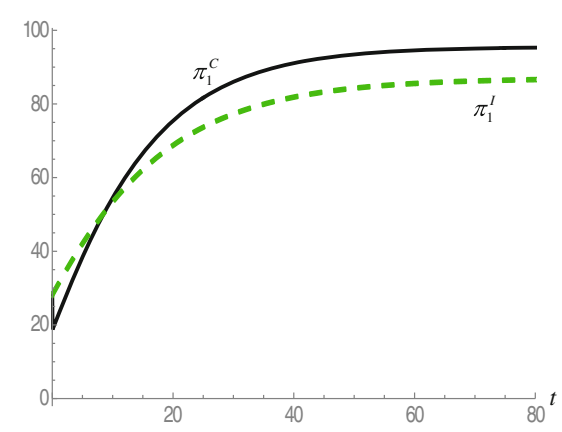

(c)

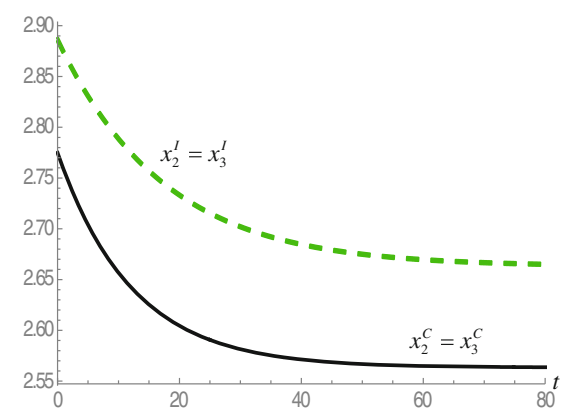

(b)

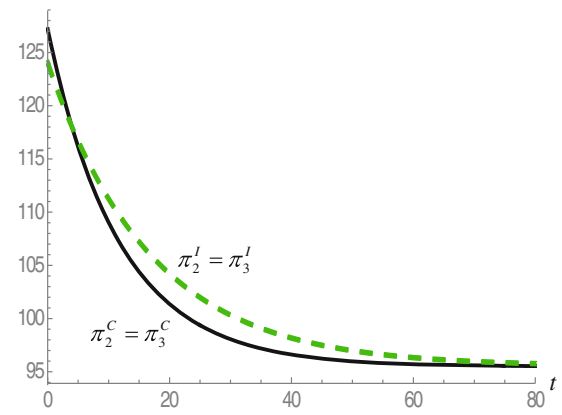

(d)

Fig. 3. Evolution of the R\&D investment of firm 1 (a) and firms 2 and 3 (b), as well as of the instantaneous profits of firm 1 (c) and firms 2 and 3 (d), for $\kappa_{i}=\kappa^{\text {const }}$ and $k_{1}(0)=0$. The solid line depicts the case in which firm 1 locates in the cluster, the dashed line corresponds to the case in which the firm locates in isolation

in isolation for different levels of the firm's knowledge stock. In Fig. 2, and also in the examination of the model dynamics, we assume the (initial) knowledge stock of the competitors to be $k_{2}=k_{3}=k^{* h}$, where $k^{* h}, h \in\{$ const, $\operatorname{lin}\}$, is their steady state knowledge stock under the two specifications for absorptive capacity and assuming that firm 1 locates in isolation. ${ }^{7}$ Panel (a) refers to the case of constant absorptive capacity. Consistently with the results in Colombo and Dawid (2014), the incentive to locate in the cluster decreases the larger $k_{1}$ is. If absorptive capacity depends on the firm's knowledge stock, the effect of $k_{1}$ on the incentives to locate in the cluster is exactly the opposite. Panel (b) of Fig. 2 highlights that the difference in the value functions of firm 1 when locating in the cluster and in isolation grows larger the more knowledge the firm has. In particular, for the level of cluster fixed cost $F$ underlying Fig. 2, the optimal location choice of firm 1 depends crucially on whether its absorptive capacity is

\footnotetext{
${ }^{7}$ It should be noted that the steady state knowledge stock differs between the case in which $\kappa_{i}=\kappa^{\text {const }}$ and that in which $\kappa_{i}=\kappa^{\text {lin }}$. In particular, for our parametrization we have that $k^{* \text { const }}=29.59$ and $k^{* \text { lin }}=30.85$.
} 
a function of its knowledge stock. When the value of $k_{1}$ is not too large compared to the steady state level $k^{*}$, then it is optimal for firm 1 to locate in isolation if its absorptive capacity depends on the knowledge stock, and in the cluster if its absorptive capacity is constant. In scenarios in which firm 1 has a large knowledge advantage compared to its competitors, the optimal location decision again differs between the cases of $\kappa_{i}=\kappa^{\text {const }}$ and $\kappa_{i}=\kappa^{\text {lin }}$. In particular, as a strong knowledge leader, firm 1 locates in the cluster only if its absorptive capacity depends on $k_{1}$.

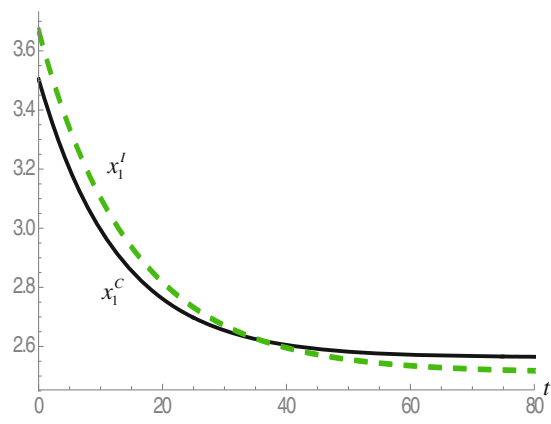

(a)

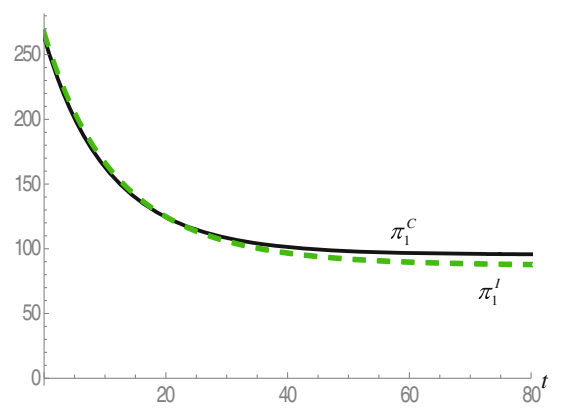

(c)

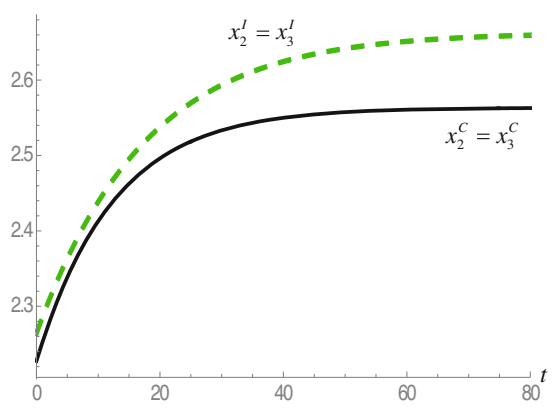

(b)

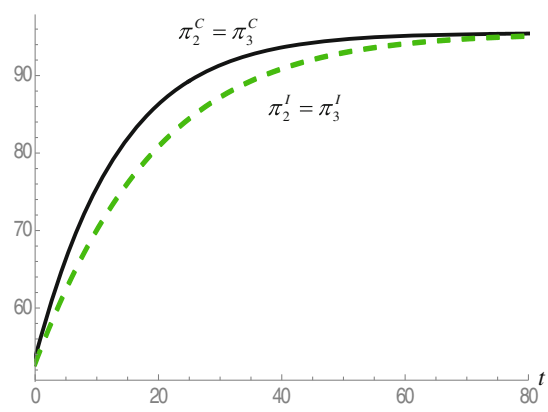

(d)

Fig. 4. Evolution of the R\&D investment of firm 1 (a) and firms 2 and 3 (b), as well as of the instantaneous profits of firm 1 (c) and firms 2 and 3 (d), for $\kappa_{i}=\kappa^{\text {const }}$ and $k_{1}(0)=70$. The solid line depicts the case in which firm 1 locates in the cluster, the dashed line corresponds to the case in which the firm locates in isolation

In order to obtain a clear understanding of the mechanisms driving the insights of Fig. 2 we first focus on the case of constant absorptive capacity. Figures 3 and 4 show the dynamics of the R\&D investments and of the instantaneous profits of all firms for the two scenarios in which $k_{1}(0)=0$ and $k_{1}(0)=70$, respectively. Figure 2 shows that it is optimal for firm 1 to locate in the cluster if $k_{1}(0)=0$, and to locate in isolation if $k_{1}(0)=70$. It can be clearly seen that, regardless of the initial knowledge stock of firm 1 , its competitors invest less in 
$R \& D$ if it locates in the cluster. Intuitively, for constant absorptive capacity, the crucial factor determining $R \& D$ investment is the expected trajectory of firm sales. If firm 1 locates in the cluster, it will benefit from a higher knowledge stock in the long run compared to the scenarios in which it locates in isolation. By knowing this, firm 1's competitors anticipate that their own market share will become smaller. Hence, they invest less in R\&D if firm 1 locates in the cluster. This strategic effect has positive implications for the profits of firm 1 and it is the dominant effect as long as the initial knowledge stock of firm 1 is not too large. In particular, panel (c) of Fig. 3 shows that, after a short initial phase, the fixed costs incurred in the cluster are more than outweighed by the strategic effect we just discussed.

Focusing now on Fig. 4, it can be seen that the initial impact of the location choice of firm 1 on the competitors' $R \& D$ investment is much smaller if $k_{1}$ is large compared to the case in which $k_{1}(0)=0$. Hence, the strategic incentive for firm 1 to locate in the cluster is much weaker when $k_{1}(0)=70$. Furthermore, if for $k_{1}(0)=70$ firm 1 locates in the cluster, its competitors will profit substantially from inward spillovers reducing their unit costs. Clearly, this also has negative implications for firm 1's profits. Overall, these effects imply that the initial time interval for which the instantaneous profits of firm 1 are larger if it locates in isolation rather than in the cluster is much longer for $k_{1}(0)=70$ than for $k_{1}(0)=0$ (cf. panel (c) of Figs. 3 and 4). Considering the instantaneous profits of firms 2 and 3 , we observe that they benefit from firm 1 locating in the cluster if the latter is a knowledge leader $\left(k_{1}(0)=70\right)$, while their profits are negatively affected if firm 1 joins the cluster with no initial knowledge.

Finally, we turn to the case of knowledge dependent absorptive capacity that is illustrated in Figs. 5 and 6 for the two situations in which $k_{1}(0)=0$ and $k_{1}(0)=70$, respectively. The two panels (b) of these figures highlight that for knowledge dependent absorptive capacity the R\&D investment of firms 2 and 3 is larger if firm 1 locates in the cluster rather than in isolation. This is exactly the opposite of what we observe in the case of constant absorptive capacity (see the corresponding panels in Figs. 3 and 4). Accordingly, if absorptive capacity depends on knowledge stock, the strategic effect on the opponents' behavior increases the incentive for firm 1 to locate in isolation. Furthermore, if the initial knowledge stock of firm 1 is small (Fig. 5) the firm cannot absorb substantial inward spillovers, at least initially. However, its own investment in $\mathrm{R} \& \mathrm{D}$ generates knowledge flows to its competitors, which have a substantially larger knowledge stock of $k^{* l i n}=30.85$. This effect weakens the competitiveness of firm 1 relative to the other firms. Hence, as it is shown in panel (c) of Fig. 5, firm 1's instantaneous profits remain larger if it locates in isolation for a long initial time window. Only in the long run the cost reductions resulting from the spillovers that emerge in the cluster become sufficiently strong to make being in the cluster more profitable. Therefore, as it can be seen in Fig. 2(b), it is optimal for firm 1 to locate in isolation if $k_{1}(0)$ is small.

Different conclusions are reached if focusing instead on the case in which $k_{1}(0)=70$, corresponding to a scenario (illustrated in Fig.6) where firm 1 


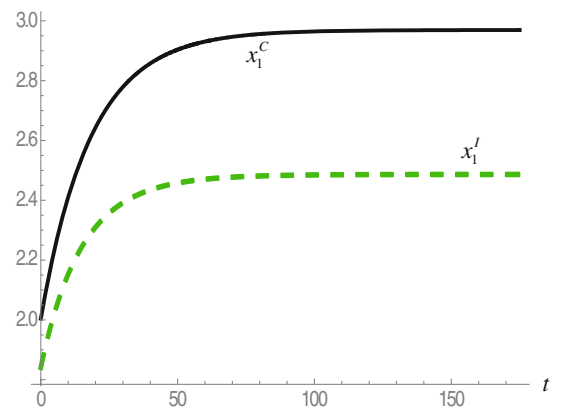

(a)

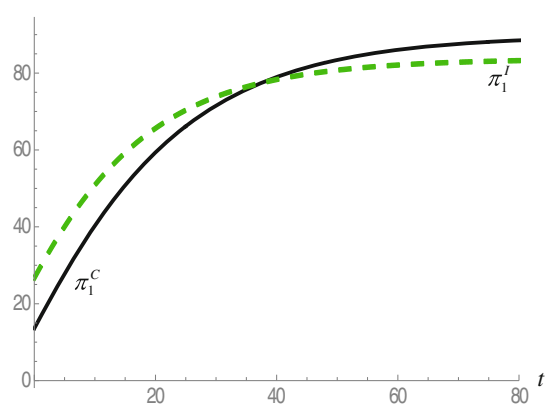

(c)

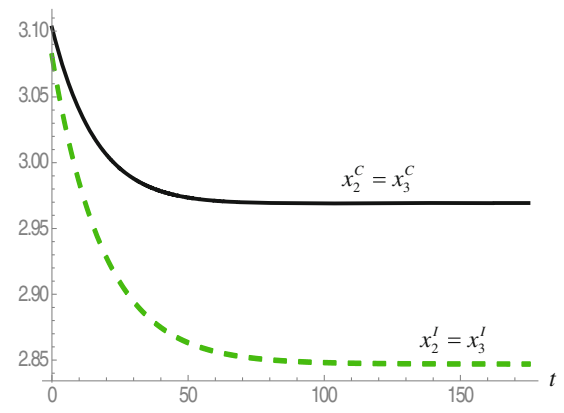

(b)

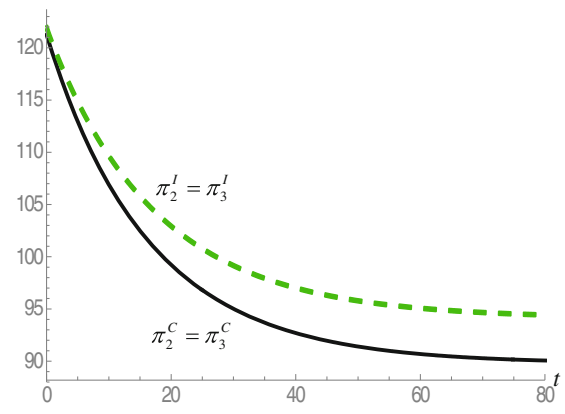

(d)

Fig. 5. Evolution of the R\&D investment of firm 1 (a) and firms 2 and 3 (b), as well as of the instantaneous profits of firm 1 (c) and firms 2 and 3 (d), for $\kappa_{i}=\kappa^{\text {lin }}$ and $k_{1}(0)=0$. The solid line depicts the case in which firm 1 locates in the cluster, the dashed line corresponds to the case in which the firm locates in isolation

has an initial knowledge advantage compared to its competitors (recall that $\left.k_{2}(0)=k_{3}(0)=30.85\right)$. In this case, firm 1 is able to greatly benefit from inward spillovers if it locates in the cluster. Due to the fact that the absorptive capacity of firm 1 is larger than that of firms 2 and 3, it is able to sustain its initial knowledge advantage over time. Taking this into account - as well as the investment incentive resulting from firm 1's goal to preserve its (high) absorptive capacity when locating in the cluster - implies that for $\kappa_{i}=\kappa^{\text {lin }}$ the R\&D investment of firm 1 is consistently larger if it locates in the cluster rather than in isolation. Also in this respect the scenario discussed here is qualitatively different from the one with constant absorptive capacity (see Fig. 4(a)). Overall, if firm 1 is a technological leader, the instantaneous profits it can achieve in the cluster become quickly larger than those it can obtain by locating in isolation, and it is therefore optimal for the firm to locate in the cluster (Fig. 2(b)). Finally, panels (d) of Figs. 5 and 6 show that if the absorptive capacity depends on the knowledge stock, then the instantaneous profits of firms 2 and 3 are always larger if firm 1 locates in isolation regardless of its initial knowledge stock. 


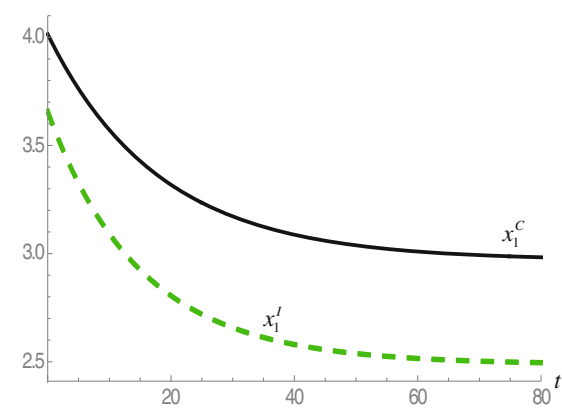

(a)

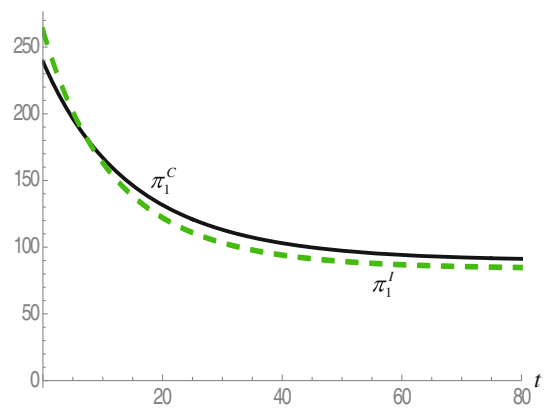

(c)

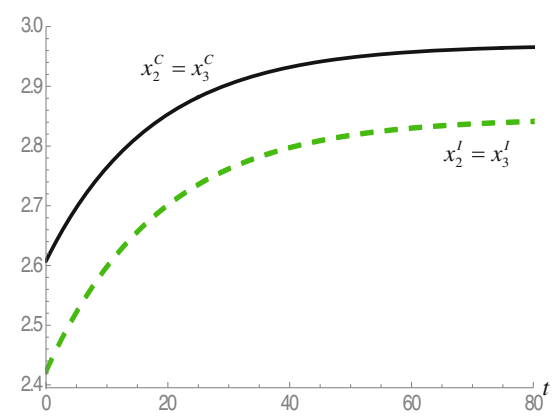

(b)

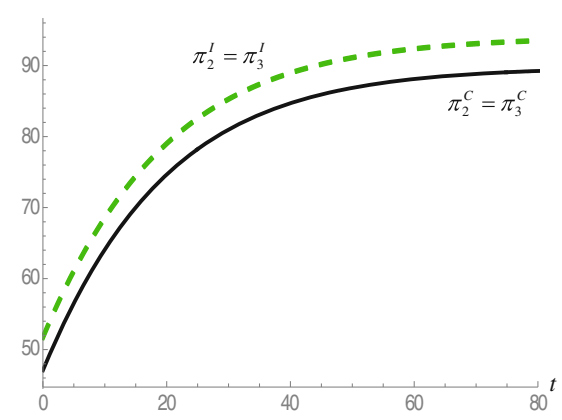

(d)

Fig. 6. Evolution of the R\&D investment of firm 1 (a) and firms 2 and 3 (b), as well as of the instantaneous profits of firm 1 (c) and firms 2 and 3 (d), for $\kappa_{i}=\kappa^{\text {lin }}$ and $k_{1}(0)=70$. The solid line depicts the case in which firm 1 locates in the cluster, the dashed line corresponds to the case in which the firm locates in isolation

\section{Concluding Remarks}

In this chapter, we augment the analysis of firms' optimal location choice in Colombo and Dawid (2014) by explicitly considering the implications of an endogenously determined absorptive capacity. In particular, we compare the benchmark of constant absorptive capacity with a scenario in which absorptive capacity is assumed to be an increasing function of the knowledge stock accumulated by a firm. We consider the differential games emerging for different location choices of a firm (cluster vs. isolation) and, by applying appropriate numerical methods, we are able to characterize the feedback strategies and the value functions associated with the Markov Perfect Equilibria of these games. We find that under endogenous absorptive capacity the relationship between the initial knowledge stock of a firm and its optimal location decision is exactly the opposite with respect to the one emerging under constant absorptive capacity. In particular, our analysis shows that for constant absorptive capacity a firm chooses to locate in an industrial cluster rather than in isolation if its initial knowledge stock is relatively small, whereas under endogenous absorptive 
capacity the initial knowledge stock has to be large (relative to that of competitors) for the firm to locate in the cluster.

Our findings highlight that a full understanding of firms' optimal location choices in different industries requires a careful examination of the characteristics of the spillovers that are associated to these choices. In particular, it is important to investigate how the ability to benefit from spillovers depends on the knowledge of the absorbing firm.

Several extensions are possible that would further enrich our analysis. First, in this study we focus on the investigation of the location choice of only one firm in a market with three competitors. Although this setting already allows us to capture the main mechanisms that are responsible for firms' location decisions, it would be interesting to develop a framework with an arbitrary number of firms, all initially choosing their locations. Second, some preliminary findings for the setting with endogenous absorptive capacity presented here suggest that, even in a model with symmetric firms, (stable) steady states exist in which firms have asymmetric knowledge stocks. This raises the question of how the long term market outcome depends on firms' initial knowledge stocks. Third, more general relationships between the knowledge stock and the absorptive capacity of a firm could be explored. Finally, more fundamental extensions of the work reported here involve the consideration of multiple locations, as well as the option for firms to relocate their activities. Exploring these issues in more details is left to future work.

\section{References}

Alcácer, J., Chung, W.: Location strategies and knowledge spillovers. Manage. Sci. 53, 760-776 (2007)

Alcácer, J., Zhao, M.: Local R\&D strategies and multilocation firms: the role of internal linkages. Manage. Sci. 58, 734-753 (2012)

Alcácer, J., Dezso, C.L., Zhao, M.: Firm rivalry, knowledge accumulation, and MNE location choices. J. Int. Bus. Stud. 44, 504-520 (2013)

Almazan, A., De Motta, A., Titman, S.: Firm location and the creation and utilization of human capital. Rev. Econ. Stud. 74, 1305-1327 (2007)

Belderbos, R., Lykogianni, E., Veugelers, R.: Strategic R\&D location by multinational firms: spillovers, technology sourcing, and competition. J. Econ. Manage. Strategy 17, 759-779 (2008)

Cohen, W.M., Levinthal, D.A.: Innovation and learning: the two faces of R\&D. Econ. J. 99, 569-596 (1989)

Colombo, L., Dawid, H.: Strategic location choice under dynamic oligopolistic competition and spillovers. J. Econ. Dyn. Control 48, 288-307 (2014)

Dawid, H., Keoula, M.Y., Kort, P.M.: Numerical analysis of markov-perfect equilibria with multiple stable steady states: a duopoly application with innovative firms. Dyn. Games Appl. (2017). Forthcoming

Dockner, E.J., Jorgensen, S., Van Long, N., Sorger, G.: Differential Games in Economics and Management Science. Cambridge University Press, Cambridge (2000)

De Beule, F., Duanmu, J.-L.: Locational determinants of internationalization: a firmlevel analysis of chinese and indian acquisitions. Eur. Manag. J. 30, 264-277 (2012) 
Ekholm, K., Hakkala, K.: Location of R\&D and high-tech production by vertically integrated multinationals. Econ. J. 117, 512-543 (2007)

Gersbach, H., Schmutzler, A.: External spillovers, internal spillovers and the geography of production and innovation. Reg. Sci. Urban Econ. 29, 679-696 (1999)

Gersbach, H., Schmutzler, A.: Foreign direct investment and R\&D-offshoring. Oxford Econ. Pap. 63, 134-157 (2011)

Griliches, Z.: The search for R\&D spillovers. Scand. J. Econ. 94, 29-47 (1992)

Head, K., Ries, J., Swenson, D.: Agglomeration benefits and location choice: evidence from Japanese manufacturing investments in the United States. J. Int. Econ. 38, 223-247 (1995)

Henisz, W.J.: The institutional environment for multinational investment. J. Law Econ. Organ. 16, 334-364 (2000)

Jaffe, A., Trajtenberg, M., Henderson, R.: Geographic localization of knowledge spillovers as evidenced by patent citations. Q. J. Econ. 108, 577-598 (1993)

Judd, K.: Numerical Methods in Economics. MIT Press, Cambridge (1998)

Lee, J.Y., Mansfield, E.: Intellectual property protection and US foreign direct investment. Rev. Econ. Stat. 78, 181-186 (1996)

Leiponen, A., Helfat, C.E.: Location, decentralization, and knowledge sources for innovation. Organ. Sci. 22, 641-658 (2011)

Mariotti, S., Piscitello, L., Elia, S.: Spatial agglomeration of multinational enterprises: the role of information externalities and knowledge spillovers. J. Econ. Geogr. 10, 519-538 (2010)

Petit, M.-L., Sanna-Randaccio, F.: Endogenous R\&D and foreign direct investment in international oligopolies. Int. J. Ind. Organ. 18, 339-367 (2000)

Piga, C., Poyago-Theotoky, J.: Endogenous R\&D spillovers and locational choice. Reg. Sci. Urban Econ. 35, 127-139 (2005)

Saxenian, A.: Regional Advantage: Culture and Competition in Silicon Valley and Route 128. Harvard University Press, Cambridge (1994)

Open Access This chapter is licensed under the terms of the Creative Commons Attribution 4.0 International License (http://creativecommons.org/licenses/by/4.0/), which permits use, sharing, adaptation, distribution and reproduction in any medium or format, as long as you give appropriate credit to the original author(s) and the source, provide a link to the Creative Commons license and indicate if changes were made.

The images or other third party material in this chapter are included in the chapter's Creative Commons license, unless indicated otherwise in a credit line to the material. If material is not included in the chapter's Creative Commons license and your intended use is not permitted by statutory regulation or exceeds the permitted use, you will need to obtain permission directly from the copyright holder. 